\title{
Special Report: 26-Year Durability of a Bioprosthesis Implanted in a 21-Year-Old Patient
}

\author{
Torulv Holst ${ }^{1}$ Josef Reichert ${ }^{2}$ Peter Haldenwang ${ }^{2}$ Vadim Moustafine ${ }^{2}$ Matthias Bechtel ${ }^{2}$ \\ Justus Strauch $^{2}$ Stephan Knipp ${ }^{1}$
}

${ }^{1}$ Department of Thoracic and Cardiovascular Surgery, West German Heart Center Essen, University Hospital, Essen, Germany

2 Department of Cardiothoracic Surgery, Ruhr-University of Bochum, Bochum, Germany

Address for correspondence Torulv Holst, MD, Department of Thoracic and Cardiovascular Surgery, West German Heart Center Essen, University Hospital, Hufelandstraße 55, Essen 45122, Germany (e-mail: torulv.holst@uk-essen.de).

Thorac Cardiovasc Surg Rep 2014;3:3-5.
Abstract
Keywords
- aortic valve
- heart valve replacement
- transapical
- transcatheter aortic valve implantation

The choice of prosthetic heart valve type is largely dependent upon patient's age at implantation and on what, in his eyes, seems more pertinent: avoidance of complications associated with anticoagulation of mechanical valves or structural valve deterioration of bioprosthetic valves. Long lasting and new promising concepts such as transcatheter aortic valve implantation are promoting the use of bioprosthesis even in younger patients. However, it is up to the individual patient to decide.

\section{Introduction}

Bioprosthetic heart valves have been used since the early 1970s with excellent hemodynamic results. However, it is commonly known that the durability of bioprosthetic valves decreases with time, particularly when implanted in younger patients. ${ }^{1}$ The need for long-term anticoagulation is minimized, and although the durability of bioprostheses is a limiting factor in long-term evaluation, tissue degeneration is usually progressive and symptomatic, thereby permitting detection during proper annual follow-up examinations. In the present case, a Carpentier - Edwards bioprosthesis, model 2650, was used. The prosthesis was made of porcine aortic valves that have been preserved in buffered glutaraldehyde and then mounted on flexible frames.

\section{Case Description}

We report on a 47-year-old man, who underwent aortic valve replacement in 1984 at the age of 21 years due to aortic isthmus stenosis combined with a valve insufficiency. First, the aortic isthmus stenosis was corrected by a patch plasty via a posterolateral thoracotomy and then the aortic valve was replaced with a 25-mm Carpentier - Edwards bioprosthesis via a median sternotomy. Postoperatively, the patient was put on oral anticoagulation with phenprocoumon for 3 months.

Twenty-six years later, in 2010, the patient developed increasing angina pectoris and progressive exercise distress. Echocardiography revealed high-grade stenosis of the implanted bioprosthesis. Using coronary angiography, relevant coronary artery disease could be precluded. Although there was a strong adhesion between the heart and the posterior sternal lamina, the reoperation was performed without complications by replacing the stenotic bioprosthesis with a $23-\mathrm{mm}$ mechanical valve prosthesis. The patient left intensive care unit on day 1 after surgery and was discharged from hospital on day 10 after surgery.

After explantation, the highly degenerated bioprosthesis was sent to Edwards Lifesciences Product Evaluation Laboratory (Irvine, California, United States) for thorough investigation. The evaluation involved gross visual examination and X-ray (-Fig. 1 ).

\section{Discussion}

Although reoperations for aortic valve replacement do not have higher mortality than first operations, the valve of choice for young patients with degenerative aortic valve received

September 30, 2013

accepted

December 6, 2013

published online

February 27, 2014
DOI http://dx.doi.org/

10.1055/s-0034-1364323. ISSN 2194-7635.
@ 2014 Georg Thieme Verlag KG
Stuttgart · New York

License terms

(1) $\Theta \circledast$ 


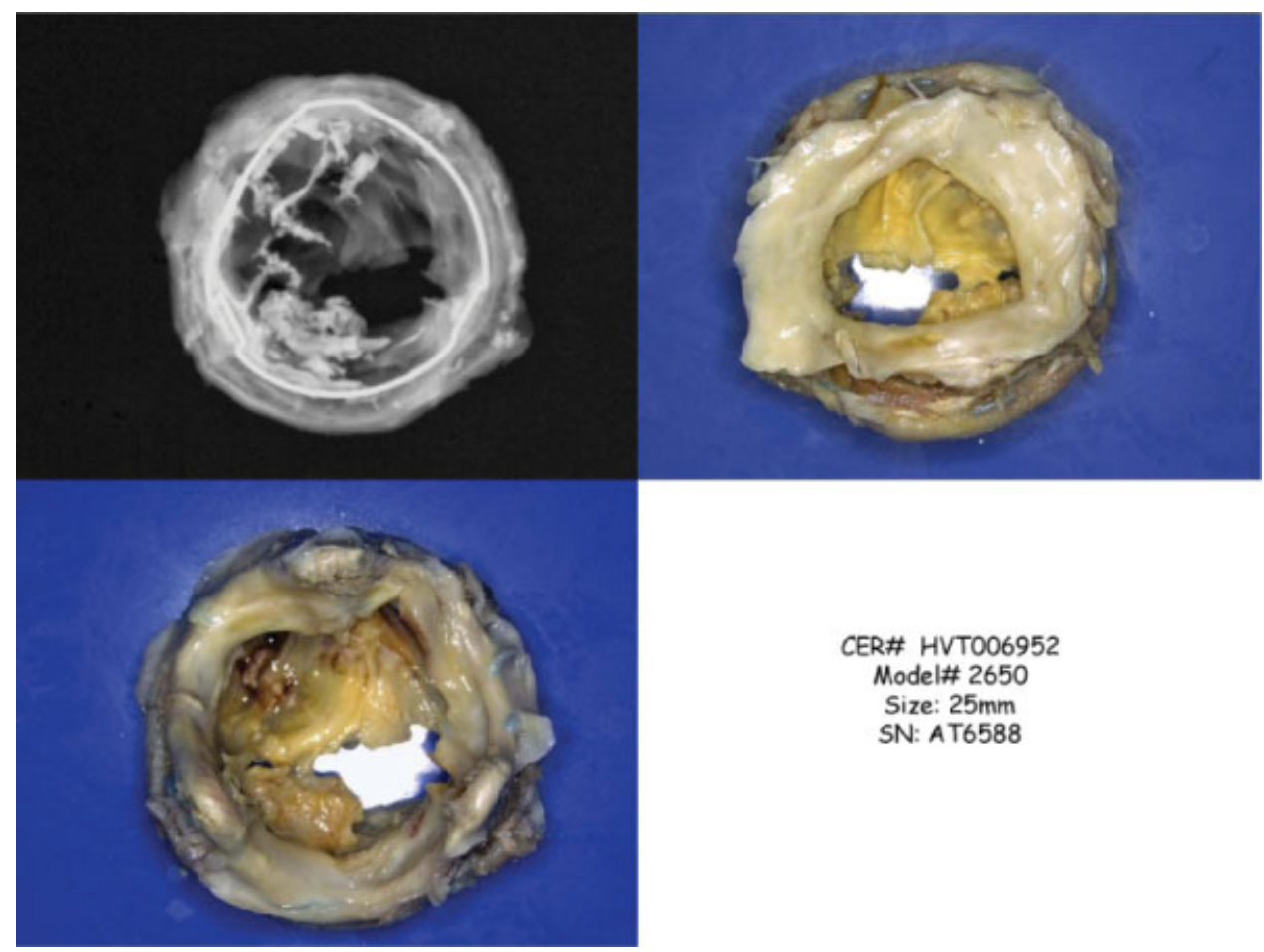

Fig. 1 Half of the noncoronary and half of the left coronary leaflet were missing due to tissue cut. Calcification was heavy in the rest of the left coronary leaflet, moderate in the right coronary leaflet, and minimal in the remaining tissue of the noncoronary leaflet. Calcification restricted the leaflets mobility and led to stenosis. Host tissue overgrowth was heavy at the stent outflow. The X-ray demonstrated calcification. Calcification is a well-recognized failure mode of bioprosthetic valves. The mechanisms of calcification are not fully understood. Host tissue/pannus growth is a complex process triggered by the interaction between the host and the device and is highly variable among patients. It is not currently possible to predict the occurrence and severity for any given patient with a bioprosthetic heart valve. However, abnormal or severe pannus growth can eventually affect the function of the valve.

disease is usually a mechanical type. ${ }^{2}$ According to the valve guidelines of the ACC/AHA of 2010, mechanical valves must be treated with phenprocoumon for the rest of the life. Side effects of permanent anticoagulation involve increased risk for serious bleeding $(0.4-2.4 \% /$ patient/year) or thromboembolic events (0.5-4.4\%/patient/year). ${ }^{3-5}$ Patient's age at the time of implantation is still the most important determinant of structural prosthetic valve deterioration ${ }^{1,6}$ : for patients 60 years and older, event-free life expectancy is superior with a bioprosthesis. While the chance of reoperation is greater, the lifetime risk of bleeding is lower compared with a mechanical prosthesis. ${ }^{7-9}$

Our patient had no valve-associated complication and was free of symptoms for 26 years, in which he could live without the risks of a permanent anticoagulation therapy. Especially in young patients, with an active lifestyle or in woman planning pregnancy, the decision about the best replacement procedure and therapy concept is still matter of debate.

As an alternative to prosthetic heart valve replacement (biological or mechanical) in young patients, in the Ross operation, the diseased aortic valve is replaced with the patient's own pulmonary valve and a pulmonary homograft is used to replace the patient's own pulmonary valve. One of the advantages of this procedure is the freedom from thromboembolism without the need for anticoagulation. Moreover, the valve seems to grow while the younger patient grows and has favorable hemodynamics in the absence of foreign valve material. Sievers et al achieved excellent midterm and longterm results after Ross procedures, including normal survival and low risk of valve-related morbidity. ${ }^{10,11}$ Further longterm follow-up studies are needed to get more certainty in this question.

It is noteworthy that autologous heart valve replacement is not a curative procedure being associated with several complications. Patients have to understand and accept the risks, and honest and open explanations should be provided to them because at the end, the patients are taking all the risks. Hence, bioprosthetic valves feature an effective and reasonable alternative to allografts and pulmonary autografts in aortic position implanted in carefully selected patients. ${ }^{12,13}$

The concept of implanting bioprostheses is supported by techniques such as the transcatheter aortic valve implantation, which provides a lower risk for reoperation via a transfemoral, transapical, or transaortic approach (valve-in-valve technique) using the metal ring of the implanted bioprosthesis as an anchor. It is conceivable that this concept is a good alternative even in young and middle-aged patients, especially when bioprostheses with a low risk of structural valve deterioration are employed.

When propagating long lasting bioprosthetic heart valve types, the question arises why we did not do this in this 
patient? On the one hand, in case of future reoperation, the minimal invasive valve-in-valve technique is highly promising and could justify implanting another bioprosthesis, but on the other hand, choosing a mechanical valve might help to prevent future surgical procedures. Our patient decided for a mechanical valve accepting its pros and cons.

\section{References}

1 Banbury MK, Cosgrove DM III, White JA, Blackstone EH, Frater RW, Okies JE. Age and valve size effect on the long-term durability of the Carpentier-Edwards aortic pericardial bioprosthesis. Ann Thorac Surg 2001;72(3):753-757

2 Davierwala PM, Borger MA, David TE, Rao V, Maganti M, Yau TM. Reoperation is not an independent predictor of mortality during aortic valve surgery. J Thorac Cardiovasc Surg 2006;131(2):329-335

3 Lund O, Nielsen SL, Arildsen H, Ilkjaer LB, Pilegaard HK. Standard aortic St. Jude valve at 18 years: performance profile and determinants of outcome. Ann Thorac Surg 2000;69(5):1459-1465

4 Prasongsukarn K, Jamieson WR, Lichtenstein SV. Performance of bioprostheses and mechanical prostheses in age group 61-70 years. J Heart Valve Dis 2005;14(4):501-508, 510-511, discussion 509

5 Santini F, Casali G, Viscardi F, et al. The CarboMedics prosthetic heart valve: experience with 1,084 implants. J Heart Valve Dis 2002;11(1):121-126, discussion 27

6 Hammermeister K, Sethi GK, Henderson WG, Grover FL, Oprian C, Rahimtoola SH. Outcomes 15 years after valve replacement with a mechanical versus a bioprosthetic valve: final report of the Veterans Affairs randomized trial. J Am Coll Cardiol 2000;36(4): $1152-1158$

7 Birkmeyer NJ, Birkmeyer JD, Tosteson AN, Grunkemeier GL, Marrin CA, O'Connor GT. Prosthetic valve type for patients undergoing aortic valve replacement: a decision analysis. Ann Thorac Surg 2000;70(6):1946-1952

8 Rahimtoola SH. Choice of prosthetic heart valve in adults: an update. J Am Coll Cardiol 2010;55(22):2413-2426

9 van Geldorp MW, Eric Jamieson WR, Kappetein AP, et al. Patient outcome after aortic valve replacement with a mechanical or biological prosthesis: weighing lifetime anticoagulant-related event risk against reoperation risk. J Thorac Cardiovasc Surg 2009;137(4):881-886, e1-e5

10 Sievers HH, Stierle U, Charitos EI, et al. Fourteen years' experience with 501 subcoronary Ross procedures: surgical details and results. J Thorac Cardiovasc Surg 2010;140(4):816-822, e1-e5

11 Charitos EI, Stierle U, Hanke T, Schmidtke C, Sievers HH, Richardt D. Long-term results of 203 young and middle-aged patients with more than 10 years of follow-up after the original subcoronary Ross operation. Ann Thorac Surg 2012;93(2):495-502

12 Smedira NG, Blackstone EH, Roselli EE, Laffey CC, Cosgrove DM. Are allografts the biologic valve of choice for aortic valve replacement in nonelderly patients? Comparison of explantation for structural valve deterioration of allograft and pericardial prostheses. J Thorac Cardiovasc Surg 2006;131(3):558-564, e4

13 Klieverik LM, Takkenberg JJ, Bekkers JA, Roos-Hesselink JW, Witsenburg M, Bogers AJ. The Ross operation: a Trojan horse? Eur Heart J 2007;28(16):1993-2000 